\title{
Efficacy of intravenous hydration drip versus amino acid drip in idiopathic oligohydramnios
}

\author{
Priti Kumar*, Aniket S. Kakade, Savita Mehendale
}

Department of Obstetrics and Gynaecology, Bharati Vidyapeeth Deemed University Medical College, Bharati Hospital and Research Centre, Dhankawadi, Pune- 411043, Maharashtra, India

Received: 24 February 2016

Revised: 27 March 2016

Accepted: 30 March 2016

\author{
*Correspondence: \\ Dr. Priti Kumar, \\ E-mail: preeti6748@gmail.com
}

Copyright: ( ) the author(s), publisher and licensee Medip Academy. This is an open-access article distributed under the terms of the Creative Commons Attribution Non-Commercial License, which permits unrestricted non-commercial use, distribution, and reproduction in any medium, provided the original work is properly cited.

\begin{abstract}
Background: Role of intravenous hydration and amino acid infusion is well documented for the treatment of foetal growth restriction and associated oligohydramnios. The present study concentrates on the efficacy of intravenous hydration and amino acid infusions in cases of isolated oligohydramnios.

Methods: 30 antenatal mothers having isolated oligohydramnios and fulfilling the inclusion criteria were selected for the study. They were randomized and administered 6 drips of normal saline or amino acid infusions. The AFI was assessed before and after the infusions. The rise in AFI, need of repeat infusions and foetal outcome was studied and analyzed.

Results: The results were tabulated with respect to age of patients, gestational age, gravida status, AFI on admission and post infusions, comparison between the two groups after the 6 drips, need of repeat infusions and the maternal and perinatal outcome. Analysis of the data was performed using Chi-Square test.

Conclusions: This study points towards the use of intravenous amino acids and normal saline in increasing the liquor in idiopathic oligohydramnios and proves useful in reducing perinatal morbidity and mortality and thus improving pregnancy outcomes, prolonging gestational age at time of delivery thereby improvement in weight gain. However the difference between the study groups was statistically not significant.
\end{abstract}

Keywords: Oligohydramnios, Intravenous Hydration, Amino acid infusion

\section{INTRODUCTION}

Amniotic fluid is marvellously dynamic milieu that changes as pregnancy progresses. The amniotic fluid contains nutrients and growth factors that facilitate foetal growth, provides mechanical cushioning and antimicrobial effect that protects the foetus and allows assessment of foetal maturity and disease.

Isolated oligohydramnios refers to the absence of significant growth restriction, normal umbilical artery Doppler velocimetry (absence of maternal and foetal risk factors) and failure to identify a recognizable underlying etiology. ${ }^{1}$
The clinical need to increase the amniotic fluid volume in pregnancies with oligohydramnios has prompted research into its normal regulation. Recently, it has been shown in the literature that amniotic fluid volume is also regulated by maternal hydration status. ${ }^{2}$ Maternal osmolality or fluid volume may have a direct impact on amniotic fluid volume. Amino infusion, intravenous fluid therapy has been used to favourably improve AFI in pregnant women with oligohydramnios. ${ }^{3}$

Amino acids cross the placenta by an active transport system and their concentration in the foetus are higher than in mother. In growth restriction associated with oligohydramnios, serum amino acids were found to be 
lower than those in normally grown foetuses. ${ }^{4}$ However no such studies are done in pregnancy complicated by isolated oligohydramnios.

The present perspective study aims at determining the efficacy of maternal administration of amino acid infusion in improving the amniotic fluid volume in cases of isolated oligohydramnios and observes its impact on the neonatal outcome.

\section{METHODS}

The duration of this study After approval by the institutional ethical committee, the study was conducted from 2013 to 2015 over a period of 2 years.

This study is experimental study designed, and the study subjects includes Healthy pregnant women admitted for oligohydramnios between gestational ages 28-34 weeks in Bharati hospital, Pune were recruited for this experimental prospective study. The sample size of this study was 30 healthy pregnant women were selected for the study after obtaining informed written consent.

\section{Inclusion criteria}

All healthy pregnant women with AFI $<8$ between gestational age of 28-34 weeks with oligohydramnios and willing to deliver in Bharati Hospital, Maharashtra, India

\section{Exclusion criteria}

\section{Patients having}

- $\quad$ Premature rupture of membranes

- Associated intrauterine growth restriction

- Multifetal pregnancy

- Threatened preterm labour

- Severe anaemia

- Foetuses having renal agenesis, suspected oesophageal atresia and other congenital anomalies

- Pre-eclampsia and eclampsia

- Chronic HTN

- Chronic renal disease

- Or any associated medical disorder

The methodology of this study was

- Step 1 The patients fulfilling the inclusion criteria were admitted after obtaining detailed history and thorough examination were investigated and subjected for USG in view of measurement of AFI. AFI was measured with four quadrant technique which consisted of measuring the largest pool of fluid devoid of cord and foetal parts found in each of the four quadrants of the uterus. All reading were taken by the same sonographer to minimize any inter observer variation. A baseline colour Doppler was done to rule out any element of foetal growth restriction. All patients underwent an admission test for foetal wellbeing.

- Step 2 Cases with AFI $<8$ were selected and randomized for I.V. hydration drip \& amino acid drip by picking up chits. Ante natal investigations were carried out as per routine protocol.

- $\quad$ Step 3 Selected cases were administered I.V. normal saline drip (500 ml)-6 drips (1 drip/day) or I.V. amino acid drip (200 ml)-6 drips (1drip/day).

- $\quad$ Step 4 AFI was measured at the end of 6 days and 1 week after the last drip by a radiologist who will be blinded.

- $\quad$ Step 5 Additional drips were given if needed as per AFI until 36 weeks of pregnancy.

- Step 6 As per the findings patient were discharged after the last drip and advised regarding proper diet, adequate oral hydration and weekly follow up.

- Step 7 Every 15 days USG was done to know the status of AFI.

- $\quad$ Step 8 Therapy to delivery interval time was noted.

- Step 9 Patients were followed till delivery and pregnancy outcome in both groups were noted. A predesigned study proforma was filled for each case. The outcome variables analyzed were age, parity, gestational age at entry into the study, pre infusion AFI, post infusion AFI, need of repeat infusions, Mode of delivery, indications for intervention, baby weight, APGAR scores and NICU stay was documented.

- Step 10 The collected data was tabulated and compared with chi-square test for significance and analyzed.

\section{RESULTS}

Table 1: The age distribution of the women studied $(n=30)$.

\begin{tabular}{|l|l|l|}
\hline Age group (Years) & No. of cases & $\%$ of cases \\
\hline $19-22$ & 6 & 20.0 \\
\hline $23-26$ & 10 & 33.3 \\
\hline $27-30$ & 12 & 40.0 \\
\hline$>30$ & 2 & 6.7 \\
\hline Total & $\mathbf{3 0}$ & $\mathbf{1 0 0 . 0}$ \\
\hline
\end{tabular}

Values are $\mathrm{n}(\%$ of cases).

The mean \pm standard error of mean (SEM) of age of the cases studied is $25.87 \pm 0.62$. The 30 cases studied, 6 cases (20.0\%) had age between 19-22years, 10 cases (33.3\%) had age between $23-26$ years, 12 cases $(40.0 \%)$ had age between 27-30years and 2 cases (6.7\%) had age more than 30 years.

The 30 cases studied, 9 cases $(30.0 \%)$ had G1 gravida, 11 cases $(36.6 \%)$ had $\mathrm{G} 2$ gravida, 8 cases $(26.7 \%)$ had G3 gravida and only 2 cases $(6.7 \%)$ had G4 gravida. 
Table 2: The distribution of gravida $(n=30)$.

\begin{tabular}{|lll|}
\hline Gravida & No. of cases & $\%$ of cases \\
\hline G1 & 9 & 30.0 \\
\hline G2 & 11 & 36.6 \\
\hline G4 & 8 & 26.7 \\
\hline Total & 2 & 6.7 \\
\hline
\end{tabular}

Values are $\mathrm{n}$ (\% of cases).

Table 3: The distribution of gestational age $(n=30)$.

\begin{tabular}{|lll|}
\hline Gestational age (weeks) & No. of cases & \% of cases \\
\hline $28-30$ & 11 & 36.6 \\
\hline $31-32$ & 8 & 26.8 \\
\hline $33-34$ & 11 & 36.6 \\
\hline Total & $\mathbf{3 0}$ & $\mathbf{1 0 0 . 0}$ \\
\hline
\end{tabular}

Values are $\mathrm{n}(\%$ of cases).

The 30 cases studied, 11 cases $(36.6 \%)$ had Gestational age between $28-30$ weeks, 8 cases $(26.8 \%)$ had Gestational age between 31-32 weeks and 11 cases (36.6\%) had Gestation age between 33-34 weeks.

Table 4: The distribution of AFI on admission $(n=30)$.

\begin{tabular}{|lll|}
\hline AFI on admission $(\mathrm{cm})$ & No. of cases & $\%$ of cases \\
\hline $5-6$ & 8 & 26.8 \\
\hline $7-8$ & 22 & 73.2 \\
\hline Total & $\mathbf{3 0}$ & $\mathbf{1 0 0 . 0}$ \\
\hline
\end{tabular}

Values are $\mathrm{n}$ (\% of cases).

The 30 cases studied, 8 cases $(26.8 \%)$ had AFI in-between 5-6 and 22 cases $(73.2 \%)$ had AFI between 7-8 on admission.

Table 5: The distribution of AFI on admission according to gestational age $(n=30)$.

\begin{tabular}{|lllll|}
\hline \multicolumn{5}{|c|}{ Gestational age (weeks) } \\
$\begin{array}{l}\text { AFI on } \\
\begin{array}{l}\text { Admission } \\
(\mathrm{cm})\end{array}\end{array}$ & $28-30$ & $31-32$ & $33-34$ & Total \\
\hline $5-6$ & 0 & $4(50.0)$ & $4(36.4)$ & $8(26.8)$ \\
\hline $7-8$ & $11(100.0)$ & $4(50.0)$ & $7(63.6)$ & $22(73.2)$ \\
\hline Total & $\mathbf{1 1}(\mathbf{1 0 0 . 0})$ & $\mathbf{8 ( 1 0 0 . 0})$ & $\mathbf{1 1}(\mathbf{1 0 0 . 0})$ & $\mathbf{3 0}(\mathbf{1 0 0 . 0})$ \\
\hline
\end{tabular}

Values are $\mathrm{n}$ (\% of cases). Chi-Square Value $=6.756, \mathrm{P}$-value $=$ $0.034^{*}$ (Statistically Significant).

The distribution of AFI on admission differs significantly across three groups of gestational age $(\mathrm{P}-\mathrm{value}<0.05)$.

The mean AFI on admission is significantly higher in normal saline group compared to the amino acid group $(\mathrm{P}$-value $<0.05)$

The mean AFI at the end of 6 drips did not differ significantly between two intervention groups (P-value>0.05).
Table 6: The comparison of AFI on admission and AFI at the end of 6 drips across two groups of intervention $(\mathbf{n}=\mathbf{3 0})$.

\begin{tabular}{|llll|}
\hline Parameters & $\begin{array}{l}\text { Amino acid } \\
(\mathbf{n}=15)\end{array}$ & $\begin{array}{l}\text { Normal saline } \\
(\mathrm{n}=15)\end{array}$ & P value \\
\hline $\begin{array}{l}\text { AFI on } \\
\text { admission }(\mathrm{cm})\end{array}$ & $6.51 \pm 0.62$ & $7.09 \pm 0.78$ & $0.033^{*}$ \\
\hline $\begin{array}{l}\text { AFI at the end } \\
\text { of 6 drips }(\mathrm{cm})\end{array}$ & $7.34 \pm 0.69$ & $7.51 \pm 1.36$ & $0.677^{\mathrm{NS}}$ \\
\hline
\end{tabular}

Values are mean \pm standard error of mean (SEM). P-values by independent sample $\mathrm{t}$ test, $\mathrm{P}$-value $<0.05$ is considered to be statistically significant. *P-value<0.05, NS: Statistically NonSignificant.

Table 7: The distribution of AFI Status at the end of 6-drips compared to the AFI on admission across two groups of intervention $(n=30)$.

\begin{tabular}{|llll|}
\hline AFI status & $\begin{array}{l}\text { Amino acid } \\
(\mathbf{n = 1 5})\end{array}$ & $\begin{array}{l}\text { Normal } \\
\text { saline }(\mathbf{n = 1 5})\end{array}$ & $\begin{array}{l}\mathbf{P} \\
\text { value }\end{array}$ \\
\hline Increased & $12(80.0)$ & $8(53.3)$ & $0.247^{\text {NS }}$ \\
\hline Decreased & 0 & $1(6.7)$ & \\
\hline No change & $3(20.0)$ & $6(40.0)$ & \\
\hline Total & $\mathbf{1 5}(\mathbf{1 0 0 . 0})$ & $\mathbf{1 5}(\mathbf{1 0 0 . 0})$ & \\
\hline
\end{tabular}

Values are $\mathrm{n}$ (\% of cases). P-value by Chi-Square test, Pvalue $<0.05$ is considered to be statistically significant. NS: Statistically Non-Significant.

The distribution of AFI Status at the end of 6-drips compared to the AFI on admission did not differ significantly across two intervention groups (P-value $>0.05)$.

Table 8: The distribution of incidence of repeat infusion across two groups of intervention $(n=30)$.

\begin{tabular}{|llll|}
\hline $\begin{array}{l}\text { Repeat } \\
\text { infusion }\end{array}$ & $\begin{array}{l}\text { Amino acid } \\
(\mathbf{n = 1 5})\end{array}$ & $\begin{array}{l}\text { Normal } \\
\text { saline }(\mathbf{n}=15)\end{array}$ & $\begin{array}{l}\text { P } \\
\text { value }\end{array}$ \\
\hline Required & $12(80.0)$ & $10(66.7)$ & $0.682^{\mathrm{NS}}$ \\
\hline Not required & $3(20.0)$ & $5(33.3)$ & \\
\hline Total & $\mathbf{1 5}(\mathbf{1 0 0 . 0})$ & $\mathbf{1 5}(\mathbf{1 0 0 . 0})$ & \\
\hline
\end{tabular}

Values are $\mathrm{n}$ (\% of cases). P-value by Chi-Square test, Pvalue $<0.05$ is considered to be statistically significant. NS: Statistically Non-Significant.

The distribution of incidence of repeat infusion did not differ significantly across two intervention groups (P-value $>0.05)$.

The distribution of gestational age at delivery differs significantly across two intervention groups (P-value<0.01).

Significantly higher proportion of cases from amino acid group had larger gestational age and significantly higher proportion of cases from normal saline group had smaller gestational age $(\mathrm{P}-\mathrm{value}<0.01)$. 
Table 9: The distribution of gestational age at delivery across two groups of intervention $(n=30)$.

\begin{tabular}{|c|c|c|c|}
\hline $\begin{array}{l}\text { Gestational } \\
\text { age (weeks) }\end{array}$ & $\begin{array}{l}\text { Amino } \\
\text { acid }(n=15)\end{array}$ & $\begin{array}{l}\text { Normal saline } \\
(\mathrm{n}=15)\end{array}$ & $P$ value \\
\hline $32-34$ & $1(6.6)$ & $6(40.0)$ & $0.004^{*}$ \\
\hline $35-37$ & $7(46.7)$ & $9(60.0)$ & \\
\hline $38-39$ & $7(46.7)$ & 0 & \\
\hline Total & $15(100.0)$ & $15(100.0)$ & \\
\hline
\end{tabular}

Values are $\mathrm{n}$ (\% of cases). P-values by Chi-Square test, $\mathrm{P}$ value $<0.05$ is considered to be statistically significant. $* \mathrm{P}$ value $<0.05$.

Table 10: The distribution of maternal outcome across two groups of intervention $(n=30)$.

\begin{tabular}{|c|c|c|c|}
\hline $\begin{array}{l}\text { Delivery } \\
\text { outcome }\end{array}$ & $\begin{array}{l}\text { Amino acid } \\
(\mathrm{n}=15)\end{array}$ & $\begin{array}{l}\text { Normal saline } \\
(\mathrm{n}=15)\end{array}$ & P-value \\
\hline LSCS & $3(20.0)$ & $6(40.0)$ & $0.232^{\mathrm{NS}}$ \\
\hline Normal & $12(80.0)$ & $9(60.0)$ & \\
\hline Total & $15(100.0)$ & $15(100.0)$ & \\
\hline
\end{tabular}

Values are n (\% of cases). P-value by Chi-Square test, Pvalue $<0.05$ is considered to be statistically significant. NS: Statistically Non-Significant.

The distribution of Delivery mode did not differ significantly across two intervention groups (Pvalue $>0.05)$.

Of the 15 cases from Amino Acid group, 12 cases $(80.0 \%)$ had normal delivery and only 3 cases $(20.0 \%)$ had LSCS delivery.

Of the 15 cases from Normal Saline group, 9 cases $(60.0 \%)$ had normal delivery and 6cases $(40.0 \%)$ had LSCS delivery.

Table 11: The distribution of birth weight across two groups of intervention $(n=30)$.

\begin{tabular}{|llll|}
\hline $\begin{array}{l}\text { Birth weight } \\
(\mathrm{gm})\end{array}$ & $\begin{array}{l}\text { Amino } \\
\text { acid }(\mathbf{n = 1 5})\end{array}$ & $\begin{array}{l}\text { Normal saline } \\
(\mathbf{n}=\mathbf{1 5})\end{array}$ & \begin{tabular}{c} 
P value \\
\hline$<2500$
\end{tabular} \\
\hline$>=2500$ & $13(13.3)$ & $11(73.3)$ & $0.001^{\text {**** }}$ \\
\hline Total & $\mathbf{1 5}(\mathbf{1 0 0 . 0})$ & $\mathbf{1 5}(\mathbf{1 0 0 . 0})$ & \\
\hline
\end{tabular}

Values are $\mathrm{n}$ (\% of cases). P-value by Chi-Square test, $\mathrm{P}$ value $<0.05$ is considered to be statistically significant. $* * * \mathrm{P}-$ value $<0.001$ (Statistically Highly Significant).

The distribution of Birth weight differs significantly across two intervention groups ( $\mathrm{P}$-value $<0.001)$.

Significantly higher proportion of cases from Amino Acid group had larger Birth weight and significantly higher proportion of cases from Normal Saline group had smaller Birth weight (P-value<0.001).

The distribution of Incidence of NICU stay differs significantly across two intervention groups (P-value<0.01).
Significantly higher proportion of cases from Normal saline group had higher incidence of NICU stay compared to amino acid group ( $\mathrm{P}$-value $<0.01)$.

Table 12: The distribution of incidence of NICU stay across two groups of intervention $(n=30)$.

\begin{tabular}{|llll|}
\hline NICU stay & $\begin{array}{l}\text { Amino acid } \\
(\mathrm{n}=15)\end{array}$ & $\begin{array}{l}\text { Normal } \\
\text { saline }(\mathrm{n}=15)\end{array}$ & $\begin{array}{c}\text { P value } \\
\text { Present }\end{array}$ \\
\hline Absent & $13(13.3)$ & $10(66.7)$ & $0.003^{* * *}$ \\
\hline Total & $15(100.0)$ & $5(33.3)$ & \\
\hline
\end{tabular}

Values are $\mathrm{n}$ (\% of cases). P-value by Chi-Square test, Pvalue $<0.05$ is considered to be statistically significant. $* * \mathrm{P}-$ value $<0.01$ (Statistically Significant).

Table 13: The distribution of APGAR score across two groups of intervention $(n=30)$.

\begin{tabular}{llll}
$\begin{array}{l}\text { APGAR } \\
\text { score }\end{array}$ & $\begin{array}{l}\text { Amino acid } \\
(\mathrm{n}=15)\end{array}$ & $\begin{array}{l}\text { Normal } \\
\text { saline }(\mathrm{n}=15)\end{array}$ & $\begin{array}{l}\mathrm{P} \\
\text { value }\end{array}$ \\
\hline At 1-min & $8.07 \pm 0.46$ & $7.53 \pm 0.52$ & $0.006^{* *}$ \\
\hline At 5-min & $8.73 \pm 0.46$ & $8.07 \pm 0.26$ & $0.001^{* * *}$ \\
\hline
\end{tabular}

Values are mean \pm standard error of mean (SEM). P-values by independent sample $\mathrm{t}$ test, $\mathrm{P}$-value $<0.05$ is considered to be statistically significant. $\quad * * \mathrm{P}$-value $<0.01 \quad$ (Statistically Significant), $\quad * * *$ P-value $<0.001 \quad$ (Statistically Highly

Significant).

The distribution of average APGAR scores (1-Min and 5Min) differs significantly across two intervention groups (P-value $<0.01$ for both).

The average APGAR score (1-Min) is significantly higher in amino acid group compared to Normal saline group $(\mathrm{P}$-value $<0.01)$.

The average APGAR score (5-Min) is significantly higher in amino acid group compared to Normal saline group (P-value<0.001).

\section{DISCUSSION}

Oligohydramnios is a late sign of foetal malnutrition. Over the years many different medical and surgical interventions have been tried to improve the liquor in oligohydramnios.

Isolated oligohydramnios refers to the absence of any significant growth restriction, normal umbilical artery Doppler velocimetry and failure to identify a recognizable underlying etiology. ${ }^{1}$ Isolated oligohydramnios has an incidence of around $30-40 \%$ of all patients with oligohydramnios.

Various studies have suggested improvement of AFI by infusion of amino acids and large amounts of glucose and even $10 \%$ maltose. Maternal hydration and infusion of amino acids is a well-known therapeutic intervention to improve the placental fluid transfer. With respect to 
physiological principles, water transfer between mother and foetus is regulated by osmotic forces, in which electrolyte gradients determine net trans-placental water exchange.

Improvement of AFI by intravenous amino acid infusion appears to act through improved maternal nutritional status, which could not have been achieved by diet because of non-compliance, socio-economic factors, worm infestation affecting gastrointestinal absorption. Pre conceptional nutritional status also plays an important role in overall development of foetus.

The present prospective study analyzed the outcome of these two major interventions in isolated oligohydramnios. There was no statistical difference in the maternal age, gestational age groups and gravida status of all the patients.

Prabha $S$ et al found that the mean age of participants in their study group at time of admission was $23 \pm 2.54 .^{5}$ This was comparable to the present study where the mean maternal age at time of admission was $25.87 \pm 0.62$.

Prabha S et al found that majority of the women in their study were primigravida $(51.2 \%) .{ }^{5}$ Whereas in the present study, majority of the women enrolled were second gravida.

In their study, Hebbar et al found that the mean gestational age at time of recruitment was 33.4 41.9 weeks. ${ }^{6}$ In the present study $36.6 \%$ cases were in the gestational age group of $28-30$ weeks and $36.6 \%$ cases in the group of 33-34 weeks.

Hebbar et al in their study found that mean AFI at the time of enrolment was 6.9 (S.D 1.7) 6; whereas Prabha S et al found that the mean AFI in their study at time of enrolment was 5.782 \pm 1.089 .5 However in the present study on admission $73.2 \%$ cases had AFI between. ${ }^{7-8}$

Table no 6 compares the AFI on admission and at the end of 6 drips points out that the mean AFI is significantly higher in normal saline group compared to amino acid group with a P-value of $<0.05$. The mean AFI at the end of 6 drips did not differ significantly between two intervention groups (P-value>0.05). Thus, there was marginal rise in AFI with both these interventions and the results were comparable in both the groups. A significant number of studies have analyzed individual variables i.e. amino acid infusion and intravenous hydration and have found encouraging results.

The end point of intervention was to achieve reasonable gestational age of around 35-36 weeks. The average gestational age at delivery in our study for amino acid group was $36.7 \pm 2.1$ weeks and normal saline group was $34.8 \pm 2.1$ (Table 9). The distribution of gestational age at delivery differs significantly across two intervention groups $(\mathrm{P}-\mathrm{value}<0.01)$. Significantly higher proportion of cases from amino acid group had larger gestational age and significantly higher proportion of cases from normal saline group had smaller gestational age ( $\mathrm{P}$-value<0.01). This was comparable with Hebbar et al who could achieve a delivery gestational age of $36.3 \pm 1.3$ weeks and they could prolong the pregnancy by 2.9 weeks where as in our study we could prolong the pregnancy by around 2.5 weeks on an average. ${ }^{6}$ The prolongation of gestational age was beneficial for the foetus as it improved their intrauterine stay and growth. There was no significant neonatal morbidity in the babies born.

The obstetric outcome of these patients has been detailed in table no 10 , it can be seen that $30 \%$ of the total sample size required a caesarean delivery, the main indication being fetal decelerations. This can be attributed to the fact that foetuses with oligohydramnios are likely to experience cord compression and variable decelerations. The incidence of caesarean delivery was high in normal saline group $(40 \%)$ in comparison with the amino acid infusion group (20\%). The difference was statistically not significant. The findings are consistent with the results observed by Hebbar et al, who found a caesarean section rate of around $62 \%$ in their study. ${ }^{6}$

The distribution of birth weight differs significantly across two intervention groups (P-value<0.001). Significantly higher proportion of cases from Amino Acid group had larger Birth weight and significantly higher proportion of cases from Normal Saline group had smaller Birth weight $(\mathrm{P}$-value $<0.001)$. This difference might be because of higher percentage $(40 \%)$ of women in normal saline group delivered between 32-34 weeks of gestation as compared to only one woman (6.6\%) in the amino acid group delivered in this gestation period. This was comparable with Shivumar PV et al in his study: the role of intravenous hydration and amino acid infusion in oligohydramnios, where amino acid drip given every alternate day in cases of oligohydramnios improved foetal weight significantly. ${ }^{7}$

The distribution of Incidence of NICU stay differs significantly across two intervention groups (Pvalue<0.01). Significantly higher proportion of cases from normal saline group had higher incidence of NICU stay compared to amino acid group (P-value $<0.01)$. This difference can be attributed to higher incidence of preterm delivery in the normal saline group as compared to the amino acid group ( $40 \%$ versus $6.6 \%$ ). There was no incidence of necrotizing enterocolitis, hypoxic ischemic encephalopathy, or sepsis in any of the baby and there was no neonatal mortality. These results were also comparable to the study by Prabha S et al. ${ }^{5}$

This study has several limitations and the foremost being a small sample size. To prove the point a study with large sample size needs to be done. Another limitation was the other confounding factors like subclinical infections, asymptomatic bacteriuria which lead to higher incidence of preterm delivery in the normal saline group. There 
should have been an equal sample size for each gestational age and the AFI group. There is continuous search for alternate suitable therapies to improve AFI in oligohydramnios.

\section{CONCLUSIONS}

Thus this study points towards the use of intravenous amino acids and normal saline in increasing the liquor in idiopathic oligohydramnios and proves useful in reducing perinatal morbidity and mortality and thus improving pregnancy outcomes, prolonging gestational age at time of delivery thereby improvement in weight gain.

However the difference between the study groups was statistically not significant. Intravenous amino acids and normal saline infusion should be offered for patients with isolated oligohydramnios so that the subsequent rise in AFI can prolong the pregnancy by few weeks and improving the neonatal outcomes. The amino acid therapy is more useful in patients with foetal growth restriction. Proper diet, rest, oral hydration and foetal surveillance have comparable outcomes as with intravenous infusions.

Intravenous normal saline drip is cost effective as compared to the amino acid group

The rise in mean AFI after infusion of amino acids and fluids indicates the possibility of intrauterine nutrient deficiency and foetal dehydration as a possible cause of oligohydramnios.
Funding: No funding sources Conflict of interest: None declared

Ethical approval: The study was approved by the Institutional Ethics Committee

\section{REFERENCES}

1. Sherer DM. A review of amniotic fluid dynamics and the enigma of isolated oligohydramnios. Am J Perinatol. 2002;19:253-66.

2. Sherer DM, Cullen JB, Thompson HO, Woods JR. Am J Obstet Gynecol. 1990;162:770-1.

3. Fisk NM, Dumit DR, Soliani A, Nicolini U, Vaughan J, Rodeck CH. Diagnostic and therapeutic transabdominal amnioinfusion in oligohydramnios. Obstet Gynecol. 1991;78:270-8.

4. Regnault TR, Friedman JE, Wilking RB, Anthony RV, Hay WW. Feto placental transport and utilization of aminoacids in IUGR- a review. Placenta. 2005;26(A);S52-62.

5. Prabha S, Vivekanand A, Sarojini A, Sethi P. The role of amino acid infusion in isolated Oligohydramnios. Perspectives in medical research. 2015;3:1-5.

6. Hebbar S, Rai L, Adiga P. Maternal hydration and Larginine supplementation improves liquor volume in patients with decreased liquor and prolongs pregnancy. Med J DY Patil Univ. 2014;7:429-34.

7. Shivkumar PV, Tayade SA, Kumar P, Tayade AT, Bagde ND, Bagde MN. The role of intravenous hydration and amino infusion in intrauterine growth restriction and oligohydramnios. Int J Biol Med Res. 2011;2:1078-83.

Cite this article as: Kumar P, Kakade AS, Mehendale S. Efficacy of intravenous hydration drip versus amino acid drip in idiopathic oligohydramnios. Int J Reprod Contracept Obstet Gynecol 2016;5:1488-93. 